\title{
DENÚNCIA E RETRATAÇÃO NA PERSPECTIVA DO EMPODERAMENTO FEMININO
}

\author{
Josiane Petry Faria* \\ Sérgio Augusto Kaesemodel ${ }^{* *}$
}

\begin{abstract}
RESUMO
A Lei Maria da Penha, para a equiparação das relações de poder, trouxe uma nova política criminal para garantir o acesso à justiça a mulheres que se encontram em situação de vulnerabilidade. Como meio de acesso, há a denúncia enquanto instrumento de exteriorização da violência e símbolo de exercício do poder e de outro lado se tem a retratação da representação. A partir de então se discute a problemática da representação e se questiona o seu significado como empoderamento feminino ou hipossuficiência, que pode significar emancipação ou falta de poder. Assim, por meio do método dedutivo se demonstra a impossibilidade de conclusão em abstrato da temática, pois existe a possibilidade de retratação da representação pode ser entendida como conquista de emancipação e igualdade material, e, por outro lado, ser interpretada como posição de submissão e falta de poder. Enfim, o caso concreto definirá dentre as duas hipóteses.
\end{abstract}

PALAVRAS-CHAVE: Denúncia; Empoderamento feminino; Representação; Retratação.

\footnotetext{
* Doutora em Direito pela Universidade de Santa Cruz do Sul (2015) com bolsa Prosup e PDSE Capes na Universidade de Sevilla/ES (2015). É professora do Programa de PósGraduação Mestrado em Direito da Universidade de Passo Fundo, PPGDireito UPF. É professora adjunto da Faculdade de Direito UPF. Vice-Presidente da Comissão da Mulher Advogada Passo Fundo/RS. Membra convidada da Comissão Estadual da Mulher Advogada. Conselheira do Conselho Municipal dos Direitos da Mulher (COMDIM). Coordenadora do projeto de extensão Projur Mulher e Diversidade. Coordenadora do grupo de pesquisa Dimensões do Poder, Gênero e Diversidade do PPGDireito. Linha de pesquisa Relações Sociais e Dimensões do Poder, com ênfase em ciências criminais, gênero, relações de poder, diversidade e direitos humanos.

** Bacharel em Ciências Jurídicas e Sociais e pesquisador do Projeto de pesquisa Dimensões do Poder, Gênero e Diversidade da Universidade de Passo Fundo.
} 


\begin{abstract}
The Maria da Penha Law, for equalization of power relations, brought a nnew criminal policy to guarantee acess to justice for women who are in a situation of vulnerability. As a means of acess, there is the complaint/denunciation as an instrument of exteriorization of violence and a symbol of the exercise of power, and on the other side there is the right of withdrawal the representation. Then, the problem of representation is discussed and its meaning is questioned as women's empowerment or hypersufficiency, which can mean emancipation or lack of power. Thus, the deductive methos demonstrates the impossibility of abstract conclusion of the thematic, since here is the possibility of the right of withdrawal of the representation can be understood as conquest of emancipation and material equality, and, on the hand, be interpreted as a position of submission and lack of power. Finally, the concrrete case will define between two hypotheses.
\end{abstract}

KEYWORDS: Complaint; Representation; Right of withdrawal; Women's Empowerment.

\title{
A INEFICÁCIA DA POLÍTICA CRIMINAL DE PROTEÇÃO À MULHER NO BRASIL
}

De início, importante mencionar que o que se entende por política criminal é o aglomerado de políticas públicas do Estado e que são voltadas para prevenir e controlar a criminalidade, já que sua extinção é impossível em qualquer meio social humano, sem prejuízo da função originária da política criminal penal, que é elencar os bens jurídicos a ser tutelados por normas penais (BIANCHINI, 2010).

A atual política criminal é totalmente diferente do que era há vinte anos atrás. O Direito Penal é incapaz de solucionar os contemporâneos problemas da criminalidade, e nós temos que refletir a respeito de algo que seja melhor, mais eficaz, que seja capaz de solucionar esses problemas (HASSEMER, 2010).

A partir desse pensamento, ideal se fazer uma análise do processo de políticas criminais adotado no Brasil, traçando um paralelo entre a eficácia da aplicação do da Lei n. 9.099/95 (Lei dos Juizados Especiais Civis e Criminais), que tem por viés uma política criminal consensualista, até a edição da Lei n. 11.340/06 (Lei Maria da Penha), que parte da elaboração de uma política criminal 
extrapenal, de caráter preventivo.

Construir uma política pública é admitir a hipótese de um novo modelo de gestão do problema da criminalidade. No Brasil, o modelo de gestão ao combate à criminalidade sempre foi aplicado, quase que exclusivamente, por meio da repressão, direito penal positivo, modelo que não mais se ampara. O ponto central é a pena privativa de liberdade, o que mostra a existência de valores por parte do Estado, reprimindo o comportamento desviante (ZOMER, 2014).

Sob esse aspecto, em se tratando de políticas criminais em relação à mulher, as reformas legislativas caminharam a passos lentos, pois, apesar de a Constituição Federal ter equiparado formalmente homens e mulheres em direitos, a igualdade material era uma realidade longínqua (OLIVEIRA, 2012).Nesse sentido, uma conquista que revolucionou o sistema de prestação jurisdicional à mulher foi a criação da Lei n. 9.099/95, precursora de uma política criminal não mais tão repressiva, baseada num modelo consensual de justiça e voltado à reparação de danos causados à vítima. Esse novo regramento estabeleceu princípios norteadores da informalidade, celeridade, oralidade e economia processual. Entretanto, havia a preocupação acerca dos limites da nova tendência para um direito penal conciliador e mais flexível, baseado na vontade da ofendida, se não colocava em risco a fragilidade das vítimas de violência doméstica (PORTO, 2014).

$\mathrm{O}$ esforço do legislador para trazer reformas no processo penal, tendo em vista torná-lo mais útil, ao preconizar menor interferência do Estado nos crimes considerados menos importantes, dividiu, metodologicamente, a criminalidade de acordo com a potencialidade lesiva da infração (GOMES, 1997). Contudo, o fato do sistema ter lançado o conflito de gênero na vala comum dos delitos de menor potencial ofensivo potencializou o problema, uma vez que as transgressões no ambiente doméstico não tinham uma ideal punição por parte do Estado (OLIVEIRA, 2012).

Os problemas advindos da implantação desse novo sistema para lidar com os conflitos de gênero levou diversos setores do campo jurídico e do movimento de mulheres a adotar uma posição de confronto e crítica aos Juizados Especiais, mormente voltado à chamada banalização da violência que, por via deles, estaria ocorrendo. Isso por causa da aplicação de medidas alternativas, como 
pagamento de cesta básica e multas, ao avesso de investir na mediação e na aplicação de medida mais adequada (AZEVEDO, 2008).

Ir contra a incidência da Lei dos Juizados Especiais criminais nada mais significa do que reação à maneira absolutamente inadequada com que a Justiça zelava a violência doméstica. A partir do momento em que a lesão corporal leve foi considerada de pequeno potencial ofensivo, surgindo a possibilidade dos conflitos serem solucionados de forma consensual, praticamente deixou de ser punida a violência intrafamiliar. $\mathrm{O}$ excesso de processos, muitas vezes, conduzia o magistrado a forçar desistências impondo acordos. O seu interesse, como forma de reduzir o volume de demandas, era não deixar que o processo se instalasse. A título de pena restritiva de direito popularizou-se de tal modo à imposição de pagamento de cestas básicas e multas, que o seu efeito punitivo foi inócuo. A vítima sentiu-se ultrajada por sua integridade física ter tão pouca valia, enquanto o agressor adquiriu a consciência de que era "barato bater na mulher". (DIAS, 2007).

Nas palavras de Lênio Streck (2004, p. 133):

Com o Juizado Especial Criminal, o Estado sai cada vez mais das relações sociais. No fundo, institucionalizou a 'surra doméstica' [...] O Estado assiste de camarote e diz: batam-se que eu não tenho nada com isso! É o neoliberalismo no Direito, agravando a própria crise da denominada 'teoria do bem jurídico', própria do modelo liberalindividualista de Direito.

Disso tudo, pode-se fazer uma leitura no sentido de que, apesar de ter sido uma tentativa válida, não há como manter esse procedimento para a resolução dos conflitos de violência doméstica. O desempenho da Lei se mostrou insuficiente para combater a violência que assola as mulheres, uma vez que, ao privilegiar a celeridade processual, reduziu a preocupação com a efetividade da justiça.

Desse modo, diante de tamanha banalidade, aliado à pressão dos movimentos feministas, bem como em observância aos tratados internacionais e a recomendação perante um Tribunal Penal Internacional, o Estado passou a elaborar uma nova legislação penal voltada à proteção da mulher que sofria violência doméstica, a chamada Lei Maria da Penha, a fim de que se garantisse uma maior 
efetividade na punição e erradicação desse tipo de violência.

Quando se percebe que a pena somente de repressão e castigo puro e simples, e que isso não irá solucionar o problema da criminalidade, sobretudo a violência de gênero, deve-se analisar novas perspectivas, que vão propiciar pensar em soluções mais efetivas em políticas públicas e em novos modelos de gestão que se tornem capazes de fazer o ciclo da criminalidade se romper em algum momento (ZOMER, 2014).

Assim, ao contrário da tendência punitivista, puramente simbólica e seletiva que sempre regeu o Congresso Nacional, a Lei Maria da Penha foi além das medidas de caráter penal, tendo o mérito no campo preventivo e de proteção à mulher. Criou mecanismos efetivos que não oprimem de forma total a liberdade do agressor e, ao mesmo tempo, protege com eficiência os bens jurídicos atinentes à mulher (PIRES, 2011).

Embora haja proteção legal às mulheres em situação de violência doméstica, o cenário de desequilíbrio e estatização do poder não deve ficar a cargo somente do Direito Penal, devendo o Estado implantar programas para que os agressores sejam submetidos a tratamentos e as vítimas recebam o protagonismo merecido. Portanto, a política criminal há de ser, também, uma política de caráter extrapenal, voltada para a implementação de ações preventivas da ocorrência do delito, a exemplo das previsões constantes da Lei n. 11.340/06, em especial os artigos. $8^{\circ}, 9^{\circ}, 35$ e as medidas protetivas (PIRES, 2011).

O principal instrumento para a aplicação dessa nova política foi a indicação para a criação de juizados especializados em violência doméstica e familiar contra a mulher. A Criação dos Juizados de Violência Doméstica e Familiar contra a Mulher (JVDFM) foi o maior de todos os avanços, sendo uma instância de justiça especializada, que não se submete ao controle das Turmas recursais (DIAS, 2007).

O legislador, ao propor a criação de uma nova instância judicial, teve como escopo garantir o acesso à justiça a mulheres em constante condição de vulnerabilidade, permitindo, ademais, a integração sistêmica entre equipes externas ao meio jurídico, conhecidas como equipes multidisciplinares. Somente profissionais de áreas diversas (psicólogos, assistentes sociais, terapeutas 
ocupacionais), motivados num propósito comum, são capazes de intervir em todas as fases do ciclo violento e prestar ajuda continuada, tornando possível a redução dos alarmantes índices de violência (ANGELIM, 2010)

Não obstante, sabe-se que o Estado é deficiente. Os dispositivos estão ali para serem usados, contudo, não há profissionais suficientes nas áreas psicossociais. Cabe, então, ao Poder Judiciário, adotar ações diretas com os agressores, e também com as vítimas, e garantir a capacitação permanente dos profissionais que atendem as vítimas e os agressores. (TELLES, 2002).

É tarefa do Estado criar meios para proteger as vítimas de violência doméstica. Ao mesmo tempo que a legislação garante direitos, o dever do Estado é prover condições de empoderamento e emancipação favoráveis para sua proteção. Exemplo disso é o que acontece com os Juizados de Violência Doméstica e Familiar contra a Mulher (JVDFM), uma vez que, diante da realidade brasileira, não há condições - ou vontade - de prover o imediato funcionamento dos juizados, acumula-se essa competência para as Varas Judiciais e Criminais, acarretando uma proteção deficiente nas áreas de cunho preventivo e assistencial, diante da inespecialidade dos profissionais, que acabam exercendo apenas a competência criminal no julgamento.

No Judiciário gaúcho, segundo a Corregedoria Geral de Justiça, os números de casos de violência doméstica não param de aumentar. Do ano de 2012 para o ano de 2014 foi constatado um aumento de 10,6\% no total de processos relativos à violência doméstica, passando de 48.830 para 54.017 processos. Para toda essa demanda, o Estado conta, atualmente, com 08 Juizados de Violência Doméstica e Familiar contra a Mulher (AJURIS, 2015).

Diante disso, resta evidente a ineficácia das políticas criminais adotadas pelo Estado brasileiro ao longo dos anos, seja na espécie normativa adotada ou na falta de efetividade prática pelo descaso da administração pública em oferecer meios para que essa nova política criminal seja eficaz. 


\section{O EMPODERAMENTO FEMININO E A DENÚNCIA COMO EXERCÍCIO DE INSTRUMENTO DO PODER}

Em sociedade, empoderamento é o equivalente, quase sinônimo, a autonomia, tendo em vista que se refere à capacidade de os indivíduos e grupos serem capazes de dirimir questões que dizem a seu respeito. Trata-se, então, de um processo pelo qual se ganha liberdade, que pode ser individual ou no sentido de uma consciência coletiva (HOROCHOVSKI, 2006).

Apesar de o tema ter recebido destaque quando se fala de gênero, seu conceito ainda é vago. $O$ que se sabe é que se trata de um processo conflituoso, uma vez que aborda situações de dominação e a busca por mudanças nas relações de poder que existem. Para se ter uma maior compreensão, há de se analisar todo um progresso social, pois atinge as mulheres de diferentes formas, tendo que se levar em consideração seu contexto de vida, subordinação e sociedade a qual pertencem (LEON, 2000). É um processo que implica em desenvolver capacidades para vencer as causas de privação das liberdades, bem como construir outras opções, ter possibilidade de escolha e executá-las para se beneficiar delas. Essas capacidades são poderes que as pessoas têm para fazer ou deixar de fazer o que tem vontade (SEN, 2001). Assim, pode-se dizer que o processo de empoderamento é bastante amplo. É, portanto, flexível e inclusivo. Não implica necessariamente na eliminação das hierarquias, mas em um processo de evolução para uma cidadania total, reconhecendo diferenças e englobando as igualdades sociais.

O propósito do empoderamento feminino é afrontar a ideologia patriarcal, mudar as sustentações e instituições que insistem em manter as discriminações de gênero e desigualdades sociais dentro da família, classes, instituições, nas leis, processos políticos, e, em capacitar as mulheres para que tenham controle de informação e de recursos materiais (BATLIWALA, 1997).

Portanto, imprescindível é compreender o papel da mulher na condição de agente, como sujeito responsável, que pode agir ou se recusar a agir, ou escolher por agir de um modo e não de outro, assumindo a responsabilidade por fazer ou não fazer as coisas. Assim, deixam de serem receptoras passivas de auxílio e passam a ser vistas como agentes de transformação social (SEN, 2001). 
Sob esse prisma, o processo de empoderamento feminino pode ser analisado sob três aspectos: o individual, o relacional e o contextual. Todos estão intimamente ligados. O primeiro, individual, diz respeito ao ato de tomar consciência de que faltam meios para conseguir realizar todo o seu potencial. Tem a consciência que deve tornar-se agente ativo e desafiar os obstáculos que lhe são impostos, tendo um nível pessoal de ganho de poder (MARTINS, 2003). O segundo, relacional, é um pouco mais abrangente, e deve olhar o contexto e em quais relações de poder o indivíduo está inserido. Aqui, para o processo de empoderamento, essencial são as influências familiares e os valores sociais que são transmitidos ao longo da vida para a mulher. Também, a formação educacional formal é ponto crucial, sendo que a educação, através do saber, é preceito fundamental para a conscientização de empoderamento e autoconfiança para participar da esfera pública. É com a boa formação escolar que as mulheres vão ter acesso a bons cargos e ter participação e representação junto ao governo (MAGESTE; MELLO; CKAGNAZAROFF). O terceiro, e último, é o contextual. Nesse tema estão incluídas as questões que dizem respeito ao bem estar, reconhecimento social individual e coletivo, economia, segurança. É onde se travam as maiores lutas e são investidos mais esforços. Aqui se trabalha com a inserção da mulher no mercado de trabalho, bem como a atuação decisória nas instâncias políticas e públicas e em organizações não governamentais que buscam por transformação social, garantindo sua efetiva participação no meio público (ROSEMBERG, 1994).

É com essa articulação de mudanças, visando melhorias pessoais, que se tem a busca pelo controle nas relações de poder. É com base nesses aspectos que os discursos feministas dão significado à luta contra a subordinação da mulher perante a estrutura social que foi toda construída em volta da figura do homem e que divide o comportamento humano pelo gênero. $\mathrm{O}$ empoderamento deve ser visto como uma ferramenta, via pela qual se estabelecerá um espaço para a mulher na sociedade contemporânea.

Frente a isso, pode-se dizer que empoderar é sinônimo de criar condições para o exercício do poder. O exercício é o modo de ação do indivíduo sobre o outro, e não apenas uma relação entre parceiros. Só há poder quando se exerce por um(s) sobre o outro(s). O poder só 
existe em ato, e seu escopo é direcionar as práticas das pessoas em ordem ao seu ajustamento estrutural. Demanda o desenvolvimento de um amplo leque de tecnologias, que têm como eixo comum a indução das motivações individuais, a modelação das vontades e o treinamento dos hábitos (RUIZ, 2004).

Nesse sentido, diz Foucault (1995, p. 243):

Ele é um conjunto de ações sobre ações possíveis; ele opera sobre o campo de possibilidades onde se inscreve o comportamento dos sujeitos ativos; ele incita, induz, desvia, facilita, ou torna mais difícil, amplia ou limita, torna mais ou menos provável; no limite, ele coage ou impede absolutamente, mas é sempre uma maneira de agir sobre um ou vários sujeitos ativos, e o quanto eles agem ou são suscetíveis de agir. Uma ação sobre ações.

Por outro lado, há de ressaltar que a nas relações de poder o outro seja reconhecido e mantido como sujeito ativo, e que se abra diante das relações de poder, um campo de reações, respostas e efeitos. Isso remete à liberdade, que entra como condição necessária para que as relações possam ocorrer. Veja-se:

Não há relação de poder onde as determinações estão saturadas - a escravidão não é uma relação de poder, pois o homem está acorrentado (trata-se então de uma relação física de coação) mas apenas quando ele pode se deslocar e, no limite, escapar. Não há, portanto, um confronto entre poder e liberdade, numa relação de exclusão (onde o poder se exerce, a liberdade desaparece); mas um jogo muito mais complexo: neste jogo, a liberdade aparecerá como condição de existência do poder (ao mesmo tempo sua precondição, uma vez que é necessário que haja liberdade para que o poder se exerça, e também seu suporte permanente, uma vez que se ela abstraísse inteiramente do poder que sobre ela se exerce, por isso mesmo desapareceria, e deveria buscar um substituto na coerção pura e simples da violência); porém, ela aparece também como aquilo que só poderá se opor a um exercício de poder que tende, enfim, a determiná-la inteiramente. (FOUCAULT, 1995, p. 244).

Isso significa que o poder se exerce apenas sobre sujeitos livres, que dispõe de um variado campo de possibilidades de atuação. Se este campo não existir ou for eliminado, não há relação de poder, mas um estado de dominação pura, saturando qualquer determinação 
no campo do exercício do poder. Quando os pensamentos e as percepções estão estruturados de conformidade com as estruturas das relações de dominação que lhes são impostas, seus atos de conhecimento são, inevitavelmente, atos de reconhecimento de submissão (BORDIEU, 2011).

A liberdade deve, então, ser considerada como ponto fundamental para a alteração de situações indesejadas. Assim, o feminismo tem papel relevante, exercendo fator de resistência na mudança das relações de poder, sendo capaz de modificar normas sociais que oprimem as mulheres. Resistir às normas é tarefa que os movimentos feministas têm adotado em diversos níveis, modificando, assim, as formas com que o poder é exercido na sociedade atual. (BORDIEU, 2011).

Nesse sentido, como fruto das batalhas feministas no campo da violência doméstica, há que se trazer a Lei Maria da Penha como um instrumento de exercício do poder, proporcionando mecanismos de proteção e exercício de cidadania. É instrumento de empoderamento em medida que, por meio da denúncia à autoridade policial, assegura direitos e medidas de segurança contra violência doméstica, proporcionando capacidade de decidir sobre atos da própria vida. O empoderamento, por meio do exercício do poder, constrói uma nova realidade.

\section{DO PROCEDIMENTO E DA IMPORTÂNCIA DA DENÚNCIA NA ÓTICA DO EMPODERAMENTO FEMININO}

O legislador, ao propor a criação de uma nova instância judicial, teve como escopo garantir o acesso à justiça a mulheres em constante condição de vulnerabilidade. Nesse norte, se tem a importância da Lei Maria da Penha, que cria mecanismos para coibir e prevenir a violência de gênero contra a mulher.

Diante disso, a mulher tem a possibilidade de exercer o poder por meio da denúncia, que pode ser entendida como poder de mando. O poder de mando é praticado de modo impositivo e até autoritário, tendo relação com o exercício do poder pela força. Para exercitar o poder, há a necessidade de mecanismos de coação externos para sua implementação. Diante da realidade da sociedade brasileira, com relação à violência doméstica e familiar, se faz necessário o uso 
desse tipo de poder, que é operado de modo pontual quando as circunstâncias assim o requerem, sendo estratégico em espaços próprios como garantia última da ordem (RUIZ, 2004). Assim, os agressores são coagidos a cumprirem determinações, prestando obediência à norma jurídica.

O poder de mando, diante da posição normatizada da mulher, é de importância, uma vez que, por meio da denúncia, há a exteriorização da violência, desocultando o poder normativo e promovendo uma consciência social contra a violência doméstica e familiar.

Pode ser considerado como um processo de legitimação do poder pelo exercício. Isso possibilita dizer que a denúncia é instrumento impugnador da dominação, indo contra a ordem vigente da estrutura social, a qual adquiriu uma dimensão simbólica densa e criou a aceitação racional da dominação, sendo, portanto, fator de transformação do status quo (RUIZ, 2004).

Nesse sentido, a denúncia há de ser tratada como política criminal, tomando a intervenção do Estado a seu favor, que propicia mecanismos para prevenir e controlar a criminalidade no intuito de atingir um reequilíbrio nas relações de poder e corrigir esse grave problema social.

Contudo, como o objetivo da presente pesquisa é analisar a viabilidade da retratação da representação, imperioso levantar o debate sobre sua viabilidade e a forma com que o direito processual penal lida com essa questão. Assim, a retratação da representação pode ser uma resposta compreensível e racional à forma como o sistema penal está estruturado. O sistema parece estar mais interessado em servir a sua própria lógica interna do que em servir à vítima. Por vezes, por meio da denúncia, a vítima quer apenas mostrar para o agressor que possui meios para atingir igualdade dentro da relação, e, assim, com o choque psicológico da possibilidade da instauração de um processo criminal, a vítima já alcançou seu objetivo, que era de produzir, por pressão externa, uma reflexão do agressor sobre sua conduta (PORTO, 2014).

Isso está intimamente conectado à conquista do empoderamento feminino, onde, como indivíduos ativos do seu próprio destino, exercem livremente o poder, assumindo a responsabilidade e deixando de serem receptoras passivas de auxílio, passando a serem agentes de transformação social (SEN, 2001). Nessa linha de raciocínio, 
posiciona-se Maria Lúcia Karam (2006, p. 06):

Quando se insiste em acusar da prática de um crime e ameaçar com uma pena o parceiro da mulher, contra sua vontade, está se subtraindo dela, formalmente dita ofendida, seu direito e seu anseio a livremente se relacionar com aquele parceiro por ela escolhido. Isto significa negar-lhe o direito à liberdade de que é titular para tratá-la como se coisa fosse, submetida à vontade de agentes do Estado que, inferiorizando-a e vitimizando-a, pretendem saber o que seria melhor para ela, pretendendo punir o homem com quem ela quer se relacionar - e sua escolha há de ser respeitada, pouco importando se o escolhido é ou não um agressor - ou que, pelo menos, não deseja que seja punido.

Assim, dentro da realidade da mulher como em processo de empoderamento, pode-se dizer que a vítima sofre duas vitimizações: a primeira decorre do próprio crime que a vitimou, e a segunda resulta do modo como é tratada pelo sistema legal, tornando-a mais objeto do que um legítimo sujeito de direitos.

O enfrentamento da violência de gênero, a superação dos resquícios patriarcais, o fim desta ou de qualquer outra forma de discriminação, vale sempre repetir, não se darão por meio da intervenção do sistema penal, que traz danos, agride e até engana. É preciso buscar instrumentos mais eficazes e menos nocivos do que o fácil, simplista e meramente simbólico apelo à intervenção do sistema penal, que, afora não realizar suas funções explícitas de proteção de bens jurídicos e evitar de condutas danosas, além de não solucionar conflitos, produz, paralelamente a injustiça decorrente da seletividade inerente à sua operacionalidade, um grande volume de sofrimento e de dor, estigmatizando, privando da liberdade e alimentando diversas formas de violência (KARAM, 2006).

Desse modo, pode-se chegar a duas conclusões: a primeira pode considerar que a retratação da representação, pela mulher em condição de vítima, representa emancipação e igualdade, tendo em vista o processo de internalização como ser ativo, capaz de dirimir as questões que fazem referência à sua esfera pessoal, bem como, como preceptora de transformação social coletiva, de conscientização de empoderamento e autoconfiança, garantindo participação efetiva no meio público, articulando mudanças e buscando controle nas relações 
de poder. Por outro lado, a retratação da representação, pode significar falta de empoderamento, vindo a ressaltar a condição de hipossuficiência em que ainda a mulher se encontra dentro da estrutura social, como ser normatizado, modelado em vontades e treinamento de hábitos, governada de forma sutil, quase invisível. Essa teia simbólica da normalidade afasta a liberdade do exercício do poder por meio de mecanismos inconscientes, impregnando no subconsciente da mulher uma falsa sensação de empoderamento, quando, na verdade, a estrutura social está se movendo em um processo racional de sujeição da figura feminina perante a relação conjugal.

\section{CONCLUSÃO}

O objetivo, com esse trabalho, foi analisar criticamente a retratação da vítima de violência doméstica, de modo a identificar se a retratação da representação pode representar emancipação da mulher perante a relação conjugal ou, por outro lado, falta de poder.

Isso vai ao encontro de um tema bastante relevante, que é o empoderamento feminino, o qual foi definido como um processo que aborda as relações de poder entre o homem e a mulher e enfrenta $o$ desequilíbrio e estatização das relações de poder, colocando em pauta as estratégias e mecanismos para a adequada circulação do poder e tomada/retomada pelas mulheres em espaços de emancipação cidadã.

Assim, ao propor uma nova política criminal para a proteção das mulheres, o Estado vem dispor de instrumentos e meios para alterar as condições de desigualdade, empoderando as mulheres, estrategicamente, nesse espaço onde ainda se encontram em posição de hipossuficiência. Nesse sentido, a denúncia pode ser inserida como meio para o exercício do poder, sendo instrumento de legitimação do empoderamento feminino. Entretanto, ao mesmo tempo que Lei Maria da Penha empodera as mulheres, o sistema penal retira sua liberdade, tornando-a objeto para que o direito penal atinja a finalidade para que é destinado.

Nesse ínterim, pode-se, então, identificar duas realidades distintas. Uma no sentido de que, a mulher, ao ter a possibilidade de se retratar da representação de violência de gênero, está num patamar de poder ao qual está em condições para solucionar em sua esfera 
pessoal o conflito que, anteriormente, levou ao conhecimento estatal. Por outro lado, a retratação da representação pode significar falta de empoderamento, reforçando a condição de hipossuficiência da mulher e dando uma falsa sensação de poder perante a sociedade, de modo que sua vontade está sujeita às condições de inferioridade em que se encontra. Nesse viés, a possibilidade de retratação da representação pode ser entendida como conquista de emancipação e igualdade material, e, por outro lado, ser interpretada como posição de submissão e falta de poder.

\section{REFERÊNCIAS}

AJURIS. http://www.ajuris.org.br/2015/03/09/semana-da-justica-pela-pazem-casa-alerta-para-combate-violencia-domestica/ Acesso em: 12/04/2016.

ANGELIM, Fábio Pereira. A importância da Intervenção Multidisciplinar Face à Complexidade da Violência Doméstica. In: LIMA, Fausto Rodrigues de Lima; SANTOS, Claudiene (Coord.). Violência doméstica: vulnerabilidades e desafios na intervenção criminal e multidisciplinar. Rio de Janeiro: Lumen Juris, 2010.

AZEVEDO, Rodrigo Ghiringhelli. Sistema Penal e Violência de Gênero: análise sociojurídica da Lei 11.340/06. 2008. Disponível em: http://www.scielo.br/pdf/se/v23n1/a05v23n1.pdf. Acesso em: 24/09/2015.

BATLIWALA, Srilatha. El significado del empoderamiento de las mujeres: nuevos conceptos desde la acción. In: LEÓN, Magdalena. Poder y empoderamiento das mujeres. TM Editores, Santa Fe de Bogotá, 1997.

BIANCHINI, Alice. A luta por direitos das mulheres. São Paulo: Carta Forense. 2007.

BOURDIEU, Pierre. A dominação masculina. Rio de Janeiro: Bertrand Brasil, 2005.

DIAS, Maria Berenice. A Lei Maria da Penha na Justiça. São Paulo: Revista dos Tribunais, 2007.

GOMES, Luiz Flávio. Suspensão condicional do processo penal. 2 ed. São Paulo: RT, 1997.

HASSEMER, Wilfried. Perspectivas de uma moderna política criminal. Revista Brasileira de Ciências Criminais | vol. 8/1994|p. 41 - 51 | Out Dez / 1994.

HOROCHOVSKI, Rodrigo Rossi. Empoderamento: definições e 
aplicações.

http://www.anpocs.org/portal/index.php?option=com_docman\&task=doc_v iew\&gid=3405\&Itemid=232. Acesso em 10/10/2015.

JESUS, Damásio E. de. Direito Penal. 2 volume. São Paulo: Saraiva, 2009.

LEÓN, Magdalena. El empoderamiento de las mujeres: encuentro del primer y tercer mundos en los estudios de género. In: La ventana: Revista de Estudios de Género. N.13. Guadalajara, 2001. pp. 94-106. Disponível na internet

em http://www.publicaciones.cucsh.udg.mx/pperiod/laventan/Ventana13/venta na13-4.pdf Acesso em 10/10/2015. Acesso em: 11/10/2015.

KARAN, Maria Lúcia. Violência de gênero: o paradoxal entusiasmo pelo rigor penal. Boletim do IBCrim, n. 168, 2006.

PORTO, Pedro Rui da Fontoura. Violência doméstica e familiar contra a mulher. Lei 11.340/06 - análise crítica e sistêmica. Livraria do Advogado, 2014.

MAGESTE, Gizelle de Souza; MELO, Marlene Catarina de Oliveira Lopes; CKAGNAZAROFF, Ivan Beck. Empoderamento de mulheres: uma proposta de análise para as organizações. Belo Horizonte, 2008. Disponível em:

http://www.anpad.org.br/diversos/trabalhos/EnEO/eneo 2008/2008 ENEO 548.pdf. Acesso em: 10/10/2015.

MARTINS, Clitia Helena Backx. Trabalhadores na reciclagem do lixo: dinâmicas econômicas, socioambientais e políticas na perspectiva de empoderamento. Tese (doutorado).Universidade Federal do Rio Grande do Sul. Programa de Pós-Graduação em Sociologia,2003.

OLIVEIRA, Elisa Rezende. Um novo modelo de justiça criminal: especialização do poder judiciário em matéria de gênero. Revista do laboratório de estudos de violência da UNESP. Disponível em: http://www2.marilia.unesp.br/revistas/index.php/levs/article/viewFile/2634/ 2064. Acesso em: 08/10/2015.

PIRES, Amom Albernaz. A opção legislativa pela política criminal extrapenal e a natureza jurídica das medidas protetivas da Lei Maria da Penha. Revista do Ministério Público do Distrito Federal e Territórios, Brasília, v. 1, n. 5, 2011.

ROSEMBERG, F. O movimento de mulheres e a abertura política no Brasil: o caso da creche- 1984. In: ROSEMBERG, F. (org.), Creche. São Paulo: Cortês/Fundação Carlos Chagas, 1994.

RUIZ, Bartolomé Castor. Os labirintos do poder: o poder (do) simbólico e 
os modos de subjetivação. Porto Alegre: Escritos, 2004.

SEN, Amartya. Desigualdade reexaminada. Rio de Janeiro; São Paulo: Record, 2001.

STRECK, L.L. O imaginário dos juristas e a violência contra a mulher: da necessidade (urgente) de uma crítica da razão cínica em Terrae Brasilis. Estudos Jurídicos, vol. 37, n. 100, 2004.

TELLES, Maria Amélia de Almeida; MELO, Mônica de. O que é violência contra a mulher.São Paulo: Brasiliense, 2002.

ZOMER, Ana Paula. Prevenção da infração penal no Estado Democrático de Direito. Disponível em: http://lexcrimen.blogspot.com.br/2014/05/prevencao-da-infracao-penal-noestado.html. Acesso em: 08/10/2015. 